\title{
Prevalence and Predictors of Maternal Anemia during Pregnancy in Gondar, Northwest Ethiopia: An Institutional Based Cross-Sectional Study
}

\author{
Mulugeta Melku, ${ }^{1}$ Zelalem Addis, ${ }^{2}$ Meseret Alem, ${ }^{3}$ and Bamlaku Enawgaw ${ }^{4}$ \\ ${ }^{1}$ Department of Hematology, School of Biomedical and Laboratory Sciences, College of Medicine and Health Sciences, \\ University of Gondar, P.O. Box 196, 6200 Gondar, Ethiopia \\ ${ }^{2}$ Department of Medical Microbiology, School of Biomedical and Laboratory Sciences, College of Medicine and Health Sciences, \\ University of Gondar, 6200 Gondar, Ethiopia \\ ${ }^{3}$ Department of Immunology and Molecular Biology, School of Biomedical and Laboratory Sciences, College of Medicine and Health \\ Sciences, University of Gondar, 6200 Gondar, Ethiopia \\ ${ }^{4}$ Department of Hematology, School of Biomedical and Laboratory Sciences, College of Medicine and Health Sciences, \\ University of Gondar, 6200 Gondar, Ethiopia
}

Correspondence should be addressed to Mulugeta Melku; mulugeta.melku@gmail.com

Received 14 August 2013; Revised 25 November 2013; Accepted 10 December 2013; Published 20 January 2014

Academic Editor: Aurelio Maggio

Copyright (C) 2014 Mulugeta Melku et al. This is an open access article distributed under the Creative Commons Attribution License, which permits unrestricted use, distribution, and reproduction in any medium, provided the original work is properly cited.

Background. Anaemia is a global public health problem which has an eminence impact on pregnant mother. The aim of this study was to assess the prevalence and predictors of maternal anemia. Method. A cross-sectional study was conducted from March 1 to April 30, 2012, on 302 pregnant women who attended antenatal care at Gondar University Hospital. Interview-based questionnaire, clinical history, and laboratory tests were used to obtain data. Bivariate and multivariate logistic regression was used to identify predictors. Result. The prevalence of anemia was $16.6 \%$. Majority were mild type (64\%) and morphologically normocytic normochromic (76\%) anemia. Anemia was high at third trimester (18.9\%). Low family income (AOR [95\% CI] = 3.1 [1.19, 8.33]), large family size $(\mathrm{AOR}[95 \% \mathrm{CI}]=4.14[4.13,10.52])$, hookworm infection $(\mathrm{AOR}[95 \% \mathrm{CI}]=2.72[1.04,7.25])$, and $H I V$ infection (AOR $[95 \% \mathrm{CI}]=5.75[2.40,13.69])$ were independent predictors of anemia. Conclusion. The prevalence of anemia was high; mild type and normocytic normochromic anemia was dominant. Low income, large family size, hookworm infection, and HIV infection were associated with anemia. Hence, efforts should be made for early diagnosis and management of HIV and hookworm infection with special emphasis on those having low income and large family size.

\section{Background}

Anaemia is a global public health problem affecting both developing and developed countries with major consequences for human health as well as social and economic development which results in a loss of billions of dollars annually [1-3]. According to the 2008 World Health Organization (WHO) report, anaemia affected 1.62 billion (24.8\%) people globally [2]. It had an estimated global prevalence of $42 \%$ in pregnant women and is a major cause of maternal mortality $[4,5]$. In Africa, $57.1 \%$ of the pregnant women were anemic. Moreover, anemia in pregnant women is a severe public health problem in Ethiopia; $62.7 \%$ of pregnant women were anemic [2]. Although the prevalence varies widely in different settings and accurate data are often lacking, in resource-limited areas terribly significant proportions of women of childbearing age particularly pregnant are anaemic [3]. Geographically, those living in Asia and Africa are at the greatest risk [1].

The effect of anemia during pregnancy on maternal and neonatal life ranges from varying degrees of morbidity to mortality. As many studies elucidated, severe anemia $(\mathrm{Hg}<7 \mathrm{~g} / \mathrm{L})$ during pregnancy has been associated with major maternal and fetal complications. It increases the risk 
of preterm delivery $[6,7]$, low birth weight [6-9], intrauterine fetal death [7], neonatal death [10], maternal mortality [11], and infant mortality [12].

Anemia is multifactorial in etiology; the disease is thought to be mainly caused by iron deficiency in developing countries. In sub-Saharan Africa where iron deficiency is common, the prevalence of anemia has often been used as a proxy for iron deficiency anemia (IDA) [3]. Other micronutrient deficiency (vitamins A and B12, riboflavin, and folic acid) has also been a cause of anemia during pregnancy [13]. Likewise, Infectious diseases such as malaria, helminthes infestations, and HIV are also implicated with high prevalence of anemia in sub-Saharan Africa [14, 15]. There was also a considerable variation in the prevalence of pregnancy anemia because of the differences in socioeconomic conditions, lifestyles, and health seeking behaviors of different population across different countries and cultures and obstetrics and gynecological related condition of pregnant mothers [16-41].

Since anaemia during pregnancy has a deleterious consequences, WHO adopted reducing maternal mortality as one of the three health-related millennium development goals so that international community is committing within this framework to reduce maternal mortality by three quarter at the end of 2015 [42]. Anemia prevalence data remains an important indicator of public health since anemia is related to morbidity and mortality in the population groups usually considered to be the most vulnerable like pregnant women. At a global level, anemia prevalence is a useful indicator to assess the impact of widespread or highly effective interventions and to track the progress made towards the goal of reducing anemia during pregnancy [43]. Anemia prevalence study is also useful to monitor the progress of reproductive health [2]. Despite the efforts made to reduce the burden, its prevalence has not been studied yet comprehensively in developing countries. Thus, the objective of this study was to determine the prevalence and predictors of anemia among pregnant women who attended ANC in Gondar University Hospital.

\section{Methods}

2.1. Study Population, Sample Size, and Sampling Procedure. The study population was pregnant mothers attending antenatal care (ANC) at Gondar University Teaching Hospital. The hospital is found in Gondar town under Amhara regional state of Ethiopia which is located at $750 \mathrm{Km}$ far from Addis Ababa, the capital city of Ethiopia, to the Northwest part of the country. The town is situated at an altitude of 2100 to 2870 meters above the sea level. According to the 2007 Ethiopian census report, Gondar has a total population of 206 and 987 and more than half $(108,902)$ of them are females [44].

A single population proportion formula, $[n=$ $\left.(Z \alpha / 2)^{2} p(1-p) / d^{2}\right]$, was used to estimate the sample size. However, due to the lack of previous studies about the prevalence of anemia during pregnancy in this particular area, $50 \%$ prevalence was used for calculation. By reviewing the records of daily flow of pregnant women for ANC utilization, about 1410 pregnant women were estimated to visit ANC clinic during the study period. Since the population during the study period was below 10,000, the sample correction formula was applied. Then, a total of 302 pregnant women who attended ANC service were selected using systematic random sampling technique from their sequence of ANC visit in the period between March and April, 2012, for two months.

2.2. Data Collection. A face-to-face interview using structured pretested questionnaire was employed to obtain data about sociodemographic, obstetric, and gynecological, dietary intake, and medical conditions of pregnant mothers. As for the current pregnancy, intake of haematinics, gestational age, ante partum hemorrhage, and dietary intake were documented. Blood pressure, weight, and height were measured and body mass index (BMI) was calculated as (weight $(\mathrm{kg}) /$ height $\left(\mathrm{m}^{2}\right)$ ). Women were then categorized into four groups according to their BMI as follows: underweight $\left(\mathrm{BMI} \leq 20 \mathrm{~kg} / \mathrm{m}^{2}\right)$, normal $\left(20 \mathrm{~kg} / \mathrm{m}^{2} \leq \mathrm{BMI} \leq 24.9 \mathrm{~kg} / \mathrm{m}^{2}\right)$, overweight (BMI of $25 \mathrm{~kg} / \mathrm{m}^{2} \leq \mathrm{BMI} \leq 29.9 \mathrm{~kg} / \mathrm{m}^{2}$ ), and obese (BMI $\geq 30 \mathrm{~kg} / \mathrm{m}^{2}$ ) [23]. A total of $6 \mathrm{~mL}$ venous blood sample was obtained from each participant. Of this, $3 \mathrm{~mL}$ of it was drawn into ethylene diamine tetraacetic acid tube for complete blood count whereas the remaining $3 \mathrm{~mL}$ was drawn to plane tube for serological tests. Participants were also requested to give fresh stool sample for parasitological examination of intestinal parasitosis.

2.3. Laboratory Analysis. Complete blood count including red blood cell count, hemoglobin concentration $(\mathrm{Hgb})$, mean cell volume (MCV), mean cell hemoglobin $(\mathrm{MCH})$, and mean cell hemoglobin concentration (MCHC), platelet count, and white blood cell count were carried out using SYXMEX KX-21 haematology analyzer (Sysmex Corporation Kobe, Japan). A thin and thick blood film had been prepared and stained with Giemsa stain for the detection and speciation of Plasmodium parasite species. Stool wet mount was prepared using saline and/or iodine and examined microscopically for identification of intestinal helminthes and protozoa parasitosis. All stool samples were processed within 30 minutes of collection. Serum and/or plasma samples were tested for HIV following the current HIV1/2 testing algorism using KHB (Shanghai Kehua bio-engineering Co., LTD., China), Statpack (Chembio Diagnostic Systems, Inc., New york, USA), and Uni-gold (Trinity Biotech Plc, Bray, Ireland). Syphilis reactivity was also tested using RPR test (Human GmbHWiesbaden, Germany) as per the manufacturer's instruction and recommendation.

2.4. Assessment of Anemia. Hgb cutoff value adjusted to sea level altitude was used to define anemia on the basis of gestational age and to classify the degree of severity using WHO criteria. The Hgb value less than $11.0 \mathrm{~g} / \mathrm{dL}$ at first and third trimesters and less than $10.5 \mathrm{~g} / \mathrm{dL}$ at second trimester was used to define anemia.Based on the severity, women with $\mathrm{Hgb}$ value of $(10 \mathrm{~g} / \mathrm{dL} \leq \mathrm{Hgb}<11 \mathrm{~g} / \mathrm{dL})$ at first and third trimesters and $(10 \mathrm{~g} / \mathrm{dL} \leq \mathrm{Hgb}<10.5 \mathrm{~g} / \mathrm{dL})$ at second trimester were classified as mild anemic. Pregnant 
women who had a $\mathrm{Hgb}$ value of $(7 \mathrm{~g} / \mathrm{dL} \leq \mathrm{Hgb}<10 \mathrm{~g} / \mathrm{dL})$ and $(\mathrm{Hgb}<7 \mathrm{~g} / \mathrm{dL})$ were categorized as moderate and severe anemic, respectively, regardless of their gestational age [45]. Manufacturer references were used to define the normal ranges for MCV (80.0-100.0 fl), MCH (27.0-33.5 pg), and MCHC (32.0-36.0 g/dL).

2.5. Data Processing and Analysis. Data were entered to EPI info version 3.5.3 and then transferred to SPSS version 20 statistical package for analysis. Descriptive and summary statistics were carried out using percentages and mean \pm SD and were presented in tables and graphs. Binary logistic regression analysis was conducted to evaluate the difference in anemia prevalence across the relevant variables. Odds ratio, Chi-square, and 95\% CI for odds ratio were computed to assess the strength of association and statistical significance in bivariate analysis. Independent variables having $P$ less than or equal to 0.2 in univariate analysis were included in multivariate analysis to control confounders in regression models. Variables having $P$ value less than 0.05 in multivariate binary logistic regression model were considered to be statistically significant.

2.6. Ethical Clearance. The study was approved by institutional review board of University of Gondar. The purpose and importance of the study were explained to each study participants. Written consent was obtained from each woman. To ensure confidentiality of participants, information, anonymous typing was used whereby the name of the participants and any participants' identifier were not written on the questionnaire, and, also during the interview to keep the privacy, they were interviewed alone. Results were communicated with clinicians working in ANC unit for appropriate management.

\section{Result}

3.1. Characteristics of the Study Participants. A total of 302 pregnant women with a mean $( \pm S D)$ age of $26.47 \pm 5.24$ years were included in the study. The majority 242 (80.1\%), 284 (94\%), 250 (82.8\%), and 194 (64.2\%) were urban dwellers, married, had attended primary school and above, and house wives by occupation, respectively. The average monthly income of the participants was 1860 Ethiopian Birr (EB) and $147(48.7 \%)$ were living with three to four family members (Table 1).

Concerning obstetrical history, $57.3 \%$ were multigravida, of whom $52.7 \%$ had an interpregnancy interval of more than or equal to 24 months and $23.7 \%$ experienced abortion. Nearly $70 \%$ of the study participants were at third trimester. Assessment of medical condition of the participant revealed that $72.5 \%$ had a normal BMI, $95.4 \%$ had no history of chronic diseases, and $4.6 \%$ had history of previous surgery. Laboratory investigation showed that $10.3 \%$ and $26.5 \%$ of the participants were reactive for HIV and infected with one or more than one intestinal parasites, respectively. A. lumbricoides (34.1\%), hookworm (25.3\%), and E. histolytica/dispar $(17.2 \%)$ were the predominant parasites found (Table 2).

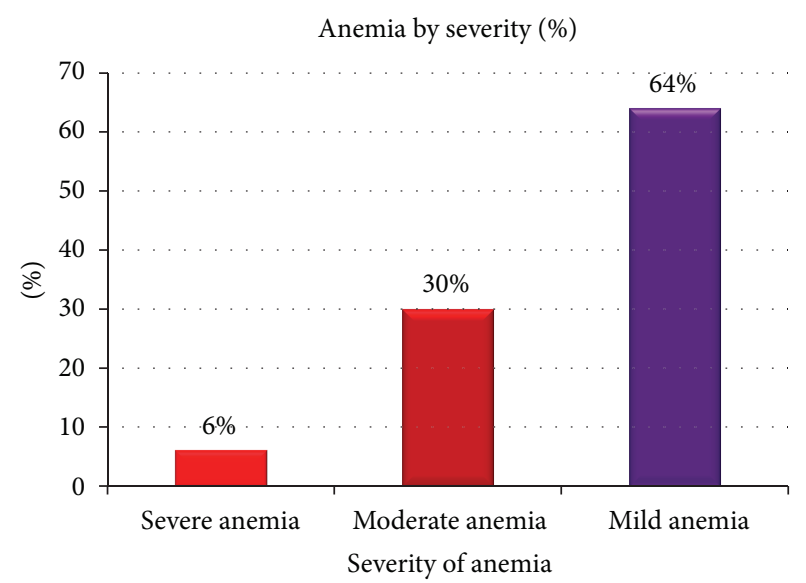

FIgURE 1: Percentage of anemia by severity among anemic pregnant women $(n=50)$.

The dietary habit and nutritional assessment revealed $19.8 \%$ did not take animal products in their current pregnancy, and $42.4 \%$ had a habit of eating green vegetables on monthly and above basis. About $80.1 \%$ had a habit of drinking coffee and tea after meal (data not shown). In their current pregnancy, $44.7 \%, 41.4 \%$, and $7.3 \%$ took iron sulfate, folic acid, and multivitamin tables as nutritional supplement, respectively (Table 3 ).

3.2. Prevalence and Predictors of Anemia. The mean Hgb level of pregnant women was $11.96 \pm 1.37 \mathrm{~g} / \mathrm{dL}$ (range: $5.85-$ $17.05 \mathrm{~g} / \mathrm{dL}$ ) and the overall prevalence of maternal anemia was $16.6 \%(n=50)$. Of the anemic women, $6 \%, 30 \%$, and $64 \%$ were severely, moderately, and mildly anemic, respectively (Figure 1).

Based on red blood cell morphologic classification of anemia, of the total anemic pregnant mothers, $76 \%$ had normocytic normochromic anemia and 14\% had microcytic hypochromic type of anemia (Table 4).

High prevalence of anemia was observed in those pregnant women who were living with more than four family members $(36.4 \%)$, illiterate $(25.7 \%)$, and whose monthly family income $<1000 \mathrm{~EB}(22 \%)$ (Table 1$)$. In addition, high prevalence rate of anemia was found among mothers who were HIV seropositive (38.7\%), infected with hookworm (34.8\%), underweighted (30\%), with more than four gravidae $(32.3 \%)$, having chronic disease $(27.3 \%)$, and at 3 rd trimester (18.9\%) (Table 2).

The prevalence of anemia among those who had a habit of eating animal products in their food stuff, not having a habit of eating vegetable, and who take tea/coffee after meal was $17.8 \%, 22.4 \%$, and $15.3 \%$, respectively. About $18.6 \%$ and $17.5 \%$ pregnant women who did not take iron sulphate and folate as nutritional therapy, respectively, were anemic (Table 3).

In bivariate analysis illiteracy, low monthly family income, large family size, underweight, gravidity, hookworm infection, and HIV seropositivity were significantly associated with maternal anemia. But in multivariate logistic regression analysis controlling the possible cofounders, only 
TABLE 1: Sociodemographic characteristics of pregnant women and prevalence of anemia by sociodemographic characteristics $(n=302)$.

\begin{tabular}{|c|c|c|c|c|}
\hline \multirow{2}{*}{ Variable } & \multicolumn{2}{|c|}{ Anemia } & \multirow{2}{*}{ Total (\%) } & \multirow{2}{*}{ COR $(95 \% \mathrm{CI})$} \\
\hline & Yes & No & & \\
\hline \multicolumn{5}{|l|}{ Age } \\
\hline year & $23(15.8)$ & $123(84.2)$ & $146(48.3)$ & 1 \\
\hline $25-29$ years & $13(15.9)$ & $69(84.1)$ & $82(27.2)$ & $1.01(0.48,2.11)$ \\
\hline$\geq 30$ years & $14(18.9)$ & $60(81.1)$ & $74(24.5)$ & $1.25(0.6,2.60)$ \\
\hline \multicolumn{5}{|l|}{ Residence } \\
\hline Rural & $11(18.3)$ & 49 (81.7) & $60(19.9)$ & $1.17(0.56,2.45)$ \\
\hline Urban & $39(16.1)$ & $203(83.9)$ & $242(80.1)$ & 1 \\
\hline \multicolumn{5}{|l|}{ Marital status } \\
\hline Married & $47(16.5)$ & $237(83.5)$ & $284(94)$ & 1 \\
\hline Others ${ }^{*}$ & $3(16.7)$ & $15(83.3)$ & $18(6)$ & $1.01(0.28,3.62)$ \\
\hline \multicolumn{5}{|l|}{ Maternal educational status } \\
\hline Illiterate & $18(25.7)$ & $52(71.3)$ & $70(23.2)$ & $3.31(1.29,8.54)^{*}$ \\
\hline Primary school & $5(9.4)$ & $48(90.6)$ & $53(17.5)$ & $0.997(0.30,3.33)$ \\
\hline Secondary school & $20(19)$ & $85(81)$ & $105(34.8)$ & $2.25(0.89-5.65)$ \\
\hline Tertiary & $7(9.5)$ & $67(90.5)$ & $74(24.5)$ & 1 \\
\hline \multicolumn{5}{|l|}{ Occupation } \\
\hline House wife & $38(19.6)$ & $156(80.4)$ & $194(64.2)$ & $2.27(0.91,5.67)$ \\
\hline Government employed & $6(9.7)$ & $56(90.3)$ & $62(20.5)$ & 1 \\
\hline Other ${ }^{* *}$ & $6(13)$ & $40(87)$ & $46(15.2)$ & $1.4(0.42,4.65)$ \\
\hline \multicolumn{5}{|l|}{ Family monthly income } \\
\hline $\mathrm{EB}$ & $30(21.9)$ & $107(78.1)$ & $137(45.4)$ & $3.22(1.28,8.13)^{*}$ \\
\hline $1000-2575 \mathrm{~EB}$ & $14(15.6)$ & $76(84.4)$ & $90(29.8)$ & $2.12(0.77,5.81)$ \\
\hline EB & $6(8)$ & $69(92)$ & $75(24.8)$ & 1 \\
\hline \multicolumn{5}{|l|}{ Family size } \\
\hline$\leq 2$ & $16(13.10)$ & $106(86.9)$ & $122(40.4)$ & \\
\hline $3-4$ & $22(15)$ & $125(85)$ & $147(48.7)$ & $1.17(0.58,2.34)$ \\
\hline$\geq 5$ & $12(36.4)$ & $21(63.6)$ & $33(10.9)$ & $3.79(1.56,9.17)^{*}$ \\
\hline
\end{tabular}

low monthly family income $(\mathrm{AOR}=3.15,95 \% \mathrm{CI}: 1.19,8.33)$, large family size $(\mathrm{AOR}=4.13,95 \% \mathrm{CI}: 1.62,10.52)$, hookworm infection $(\mathrm{AOR}=5.75,95 \% \mathrm{CI}: 2.40,13.69)$, and $\mathrm{HIV}$ seropositivity $(\mathrm{AOR}=2.72,95 \% \mathrm{CI}: 1.014,7.25)$ remained being independent predictors of pregnancy anemia (Table 5).

\section{Discussion}

The overall prevalence of anemia was $16.6 \%$ (95\%CI (12.6, 20.6)). This prevalence was comparable to studies conducted in Trinidad and Tobago (15.3\%) [16], Thailand (20.1\%) [17], Zurich (18.5\%) [45], Hawassa (15.3\%) [39], and Gondar town (22\%) [46].

The prevalence is considerably lower than previous study reports from Malaysia (35\%), Jordan (34.7\%), Vietnam (43.2\%), Southeastern Nigeria (76.9\%), Eastern Sudan (62.6\%), and Jimma, Ethiopia (38.2\%) [22, 23, 25, 35, 38, 41]. The possible reason for the difference may be resulted from geographical variation of factors across different areas. In addition, lower prevalence can be attributed to gradual improvement of life style and living standards and health seeking behavior by the effort of government to achieve the
Millennium development goal aimed to reduce the maternal mortality by three-quarter by year 2015. In support of this argument, the prevalence of anemia in women of age 15-49 years had decreased from $27 \%$ in 2005 to $17 \%$ by the year 2011 in Ethiopia [47].

In this study, mild anemia was common followed by moderate anemia. This is consistent with reports from Africa and elsewhere in the world [23, 25, 29, 31, 39]. This study tried to demonstrate the common morphological characteristic of anemia among pregnant mothers. Of the total anemic pregnant women, $76 \%$ had normocytic normochromic anemia followed by microcytic hypochromic type which is in agreement with a report from Turkey [18] and Azezo, Gondar town [46].

This study demonstrated that mothers who have low monthly family income were three times more likely to be anemic as compared to those with high monthly family income. This is in agreement with some studies [24, 29] and contradicted to other reports [22, 23, 40, 41]. According to the 2007 Ethiopian central statistical agency household income consumption and expenditure survey, more than $57 \%$ of the total expenditure is spent on food [48]. Moreover, in 
TABLE 2: The prevalence of anemia according to the obstetrics and medical factors $(n=302)$.

\begin{tabular}{|c|c|c|c|c|}
\hline \multirow{2}{*}{ Variable } & \multicolumn{2}{|c|}{ Anemic } & \multirow{2}{*}{ Total (\%) } & \multirow{2}{*}{ COR $(95 \% \mathrm{CI})$} \\
\hline & Yes (\%) & No (\%) & & \\
\hline \multicolumn{5}{|l|}{ Gravidity } \\
\hline Primigravidae & 15 (11.6) & $114(88.4)$ & $129(42.7)$ & 1 \\
\hline Secundigravidae & $11(14.3)$ & $66(85.7)$ & $77(25.5)$ & $1.27(0.55,2.92)$ \\
\hline 3-4 gravidae & $14(21.5)$ & $51(78.5)$ & $65(21.5)$ & $2.09(0.94,4.65)$ \\
\hline$\geq 5$ gravidae & $10(32.3)$ & $21(67.7)$ & $31(10.3)$ & $3.62(1.43,9.17)^{*}$ \\
\hline \multicolumn{5}{|l|}{ History of abortion } \\
\hline Yes & $8(19.5)$ & $33(80.5)$ & $41(23.7)$ & $0.94(0.391,2.27)$ \\
\hline No & $27(20.4)$ & $105(79.6)$ & $132(76.3)$ & 1 \\
\hline \multicolumn{5}{|l|}{ Interpregnancy interval } \\
\hline \multirow[t]{2}{*}{ 1st pregnancy } & $15(11.6)$ & $114(88.4)$ & $129(42.7)$ & 1 \\
\hline & $2(14.3)$ & $12(85.7)$ & $14(4.6)$ & $1.27(0.26,6.21)$ \\
\hline$\geq 24$ months & $33(20.8)$ & $126(79.2)$ & $159(52.7)$ & $2(1.03,3.86)$ \\
\hline \multicolumn{5}{|l|}{ Gestational age } \\
\hline 1st trimester & $1(12.5)$ & $7(87.5)$ & $8(2.6)$ & 1 \\
\hline 2nd & $12(12.2)$ & $86(87.8)$ & $98(32.5)$ & $0.98(0.11,8.62)$ \\
\hline $3 \mathrm{rd}$ & $37(18.9)$ & $159(81.1)$ & $196(64.9)$ & $1.63(0.19,13.65)$ \\
\hline \multicolumn{5}{|l|}{ Body mass index } \\
\hline Underweight & $9(30)$ & $21(70)$ & $30(10)$ & $2.42(1.03,5.64)^{*}$ \\
\hline Normal and above & $41(15.1)$ & $231(84.9)$ & $272(90)$ & 1 \\
\hline \multicolumn{5}{|c|}{ Presence of chronic disease } \\
\hline Yes & $4(27.3)$ & $11(72.7)$ & $14(4.6)$ & $1.4(0.38,5.21)$ \\
\hline No & $47(16.3)$ & $241(83.7)$ & $288(95.4)$ & 1 \\
\hline \multicolumn{5}{|c|}{ Presence of peptic ulcer disease } \\
\hline Yes & $20(18.3)$ & $89(81.7)$ & $109(36.1)$ & $1.22(0.66,2.27)$ \\
\hline No & $30(15.5)$ & $163(84.5)$ & $193(63.9)$ & 1 \\
\hline \multicolumn{5}{|c|}{ History of previous surgery } \\
\hline Yes & $2(14.3)$ & $12(85.7)$ & $14(4.6)$ & $0.83(0.181,3.84)$ \\
\hline No & $48(16.7)$ & $240(83.3)$ & $288(95.4)$ & 1 \\
\hline \multicolumn{5}{|c|}{ Malaria attack in current pregnancy } \\
\hline Yes & $3(20)$ & $12(80)$ & $15(5)$ & $1.28(0.347,4.7)$ \\
\hline No & $47(16.4)$ & $240(83.6)$ & $287(95)$ & 1 \\
\hline \multicolumn{5}{|l|}{ Hookworm infection } \\
\hline Yes & $8(34.8)$ & $15(65.2)$ & $23(7.6)$ & $3.01(1.20,7.52)^{*}$ \\
\hline No & $42(15.1)$ & $237(84.9)$ & $279(92.4)$ & 1 \\
\hline \multicolumn{5}{|l|}{ HIV infection } \\
\hline Reactive & $12(38.7)$ & $19(61.3)$ & $31(10.3)$ & $3.87(1.74,8.62)^{*}$ \\
\hline Nonreactive & $38(14)$ & $233(86)$ & $271(89.7)$ & 1 \\
\hline \multicolumn{5}{|l|}{ Syphilis } \\
\hline Reactive & $3(27.3)$ & $8(72.7)$ & $11(3.6)$ & $1.95(0.5,7.61)$ \\
\hline Nonreactive & $47(16.2)$ & $244(83.8)$ & $291(96.4)$ & 1 \\
\hline
\end{tabular}

${ }^{*}$ Significant $(P<0.05)$ in bivariate analysis. Chronic disease comprises hypertension, kidney disease, cardiac problems, and diabetes mellitus.

this study, $80 \%$ of study participants were from urban area suggesting that they are food net buyers. As income is low, the expenditure for food becomes low. Besides, due to food price inflation, the purchasing power of income is low. So, low income groups did not get adequate nutrition and thereby low family income groups were at risk of anemia.

According to the results of our study, pregnant mothers who had been living within a family of more than four members were more likely to be anemic compared to those living with $\leq 2$ family members. Nevertheless, in Jordan [23], there was no significant difference of anemia prevalence between groups of pregnant mothers living with varying family sizes. This difference may be attributed as in Jordan case; the study was undertaken in rural district where there was not great variation in family size and income. But, in this study, $80 \%$ of pregnant women were in urban areas having 
TABLE 3: Prevalence of anemia in relation to dietary habit, ANC followup, and nutrient supplementation at their current pregnancy period $(n=302)$.

\begin{tabular}{|c|c|c|c|c|}
\hline \multirow{2}{*}{ Variable } & \multicolumn{2}{|c|}{ Anemia } & \multirow{2}{*}{ Total $(N=302)$} & \multirow{2}{*}{$\operatorname{COR}(95 \% \mathrm{CI})$} \\
\hline & Yes & No & & \\
\hline \multicolumn{5}{|c|}{ Eating meat and animal products } \\
\hline Yes & $43(17.8)$ & $199(82.2)$ & $242(80.1)$ & 1 \\
\hline No & $7(11.7)$ & $53(88.3)$ & $60(19.9)$ & $0.61(0.26,1.44)$ \\
\hline \multicolumn{5}{|c|}{ Eating green leafy vegetables } \\
\hline Yes & $39(15.4)$ & $214(84.6)$ & $253(83.8)$ & 1.00 \\
\hline No & $11(22.4)$ & $38(77.6)$ & $49(16.2)$ & $1.6(0.75,3.372)$ \\
\hline \multicolumn{5}{|c|}{ Taking fruit after meal } \\
\hline Yes & $34(16.6)$ & $172(83.5)$ & $206(68.2)$ & 1 \\
\hline No & $16(16.7)$ & $80(83.3)$ & $96(31.8)$ & $1.012(0.53,1.94)$ \\
\hline \multicolumn{5}{|c|}{ Taking coffee or tea immediately after meal } \\
\hline Yes & $37(15.3)$ & $205(84.7)$ & $242(80.1)$ & $0.65(0.32,1.32)$ \\
\hline No & $13(21.7)$ & $47(78.3)$ & $60(19.9)$ & 1 \\
\hline \multicolumn{5}{|c|}{ ANC followup during current pregnancy } \\
\hline Yes & $28(16.1)$ & $146(83.9)$ & $174(57.6)$ & 1 \\
\hline No & $22(17.2)$ & $106(82.8)$ & $128(42.4)$ & $1.08(0.59,1.99)$ \\
\hline \multicolumn{5}{|c|}{ Iron sulphate table intake in current pregnancy } \\
\hline Yes & $19(14.1)$ & $116(85.9)$ & $135(44.7)$ & 1 \\
\hline No & $31(18.6)$ & $136(81.4)$ & $167(55.3)$ & $1.39(0.75,2.59)$ \\
\hline \multicolumn{5}{|c|}{ Folic acid intake in current pregnancy } \\
\hline Yes & $19(15.2)$ & $106(84.8)$ & $125(41.4)$ & 1 \\
\hline No & $31(17.5)$ & $146(82.5)$ & $177(58.6)$ & $1.19(0.64,2.2)$ \\
\hline \multicolumn{5}{|c|}{ Multivitamin intake in current pregnancy } \\
\hline Yes & $3(13.6)$ & $19(86.4)$ & $22(7.3)$ & 1 \\
\hline No & $47(16.8)$ & $233(83.2)$ & $280(92.7)$ & $1.28(0.36,4.49)$ \\
\hline
\end{tabular}

TABLE 4: Distribution of morphologic type anemia among study participants.

\begin{tabular}{|c|c|c|c|}
\hline \multirow[b]{2}{*}{ Morphologic type of cells } & \multicolumn{3}{|c|}{ Anemic status } \\
\hline & $\begin{array}{c}\text { Anemic } \\
n(\%)\end{array}$ & $\begin{array}{c}\text { Not anemic } \\
n(\%)\end{array}$ & $\begin{array}{l}\text { Total } \\
n(\%)\end{array}$ \\
\hline Microcytic hypochromic $(\mathrm{MCV}<80 \mathrm{fl}, \mathrm{MCH}<27 \mathrm{pg})$ & $8(16 \%)$ & $1(0.4 \%)$ & $9(3.0 \%)$ \\
\hline Normocytic Normochromic (MCV and MCH within the normal value) & $38(76 \%)$ & $235(93.2 \%)$ & $273(90.4 \%)$ \\
\hline Macrocytic normochromic $(\mathrm{MCV}>100 \mathrm{fl}, \mathrm{MCH}(27 \mathrm{pg}<\mathrm{MCH}<33.5 \mathrm{pg}))$ & $2(4 \%)$ & $5(1.98 \%)$ & $7(2.3 \%)$ \\
\hline Other combinations & $2(4 \%)$ & $11(4.37 \%)$ & $13(4.3 \%)$ \\
\hline Total & $50(16.6 \%)$ & $252(83.4 \%)$ & $302(100 \%)$ \\
\hline
\end{tabular}

varying income levels and $20 \%$ in rural areas with varying family size.

This study also showed that the proportion of anemia among pregnant women who had been infected with HIV was significantly higher compared to those noninfected that is six times at higher risk. This is in line with previous studies [29, 31-33, 35]. This increased prevalence of anemia among HIV seropositive pregnant women may be explained by the fact that HIV infection is associated with lower serum folate, vitamin B12, and ferritin in pregnancy [31]. In addition, Anemia in HIV/AIDS patients may arise from a number of causes, including deregulation of the host immune system leading to destruction or inhibition of hematopoietic cells [49].
In our study, hookworm has increased the risk of being anemic and this finding was consistent with other studies $[26,41,46]$. This is because adult hookworm parasites attach and injure upper intestinal mucosa and also ingest blood. This brings about gastrointestinal blood loss and induces depletion of iron, folic acid, and vitamin B12 that ultimately anemia $[13,50]$.

Even though it was not statistically significant in multivariate logistic regression (but significant in bivariate analysis), multigravida and grand gravida had high odds for anemia as compared to primigravidae. Likewise, studies in Malaysia [22], Burkina Faso [29], Sudan [38], and Jimma [41] reported that gravidity did not have statistically significant contribution for difference in anemia prevalence. 
TABLE 5: Multivariate binary logistic regression analysis of pregnancy anemia with predictor variables $(n=302)$.

\begin{tabular}{|c|c|c|c|c|c|}
\hline \multirow{2}{*}{ Variables } & \multicolumn{2}{|c|}{ Anemia } & \multirow{2}{*}{ Total } & \multicolumn{2}{|c|}{ OR $(95 \% \mathrm{CI})$} \\
\hline & Yes & No & & COR $(95 \% \mathrm{CI})$ & AOR $(95 \% \mathrm{CI})$ \\
\hline \multicolumn{6}{|l|}{ Maternal educational status } \\
\hline Illiterate & $18(25.7)$ & $52(74.3)$ & 70 & $3.31(1.29,8.54)$ & $0.61(0.14,2.68)$ \\
\hline Primary & $5(9.4)$ & $48(90.6)$ & 53 & $0.997(0.30,3.33)$ & $0.37(0.08,1.73)$ \\
\hline Secondary & $20(19)$ & $85(81)$ & 105 & $2.25(0.89-5.65)$ & $0.99(0.30,3.22)$ \\
\hline Tertiary & $7(9.5)$ & $67(90.5)$ & 74 & 1 & 1 \\
\hline \multicolumn{6}{|l|}{ Family income/month } \\
\hline Low (<1000 birr) & $30(21.9)$ & $107(78.1)$ & 137 & $3.22(1.28,8.13)$ & $3.15(1.19,8.33)^{*}$ \\
\hline Medium (1000-2575 birr) & $14(15.6)$ & $76(84.4)$ & 90 & $2.12(0.77,5.81)$ & $1.80(0.62,5.18)$ \\
\hline High (>2575 birr) & $6(8)$ & $69(92)$ & 75 & 1 & 1 \\
\hline \multicolumn{6}{|l|}{ Family size } \\
\hline$\leq 2$ & $16(13.1)$ & $106(86.9)$ & 122 & 1 & 1 \\
\hline 3-4 members & $22(15)$ & $125(85)$ & 147 & $1.17(0.58,2.34)$ & $1.03(0.49,2.13)$ \\
\hline$\geq 5$ members & $12(36.4)$ & $21(63.6)$ & 33 & $3.78(1.56,9.17)$ & $4.13(1.62,10.52)^{* *}$ \\
\hline \multicolumn{6}{|l|}{ Body mass index } \\
\hline Underweight $\left(<20 \mathrm{~kg} / \mathrm{m}^{2}\right)$ & $9(30)$ & $21(70)$ & 30 & $2.42(1.03,5.64)$ & $2.27(0.83,6.21)$ \\
\hline Normal and above $\left(\geq 20 \mathrm{~kg} / \mathrm{m}^{2}\right)$ & $41(15.1)$ & $231(84.9)$ & 272 & 1 & 1 \\
\hline \multicolumn{6}{|l|}{ Gravidity } \\
\hline Primigravidae & $15(11.6)$ & $114(88.4)$ & 129 & 1 & 1 \\
\hline Secungravidae & $11(14.3)$ & $66(85.7)$ & 77 & $1.27(0.55,2.91)$ & $1.1(0.37,3.08)$ \\
\hline 3-4 gravidae & $14(21.5)$ & $51(78.5)$ & 65 & $2.09(0.94,4.65)$ & $2.19(0.68,6.99)$ \\
\hline$\geq 5$ gravidae & $10(32.3)$ & $21(67.7)$ & 31 & $3.62(1.43,9.17)$ & $1.87(0.31,11.36)$ \\
\hline \multicolumn{6}{|l|}{ Hookwarm } \\
\hline Yes & $8(34.8)$ & $15(65.2)$ & 23 & $3.01(1.2,7.52)$ & $2.72(1.01,7.25)^{*}$ \\
\hline No & $42(15.1)$ & $237(84.9)$ & 279 & 1 & 1 \\
\hline \multicolumn{6}{|l|}{ HIV } \\
\hline Yes & $12(38.7)$ & $19(61.3)$ & 31 & $3.9(1.74,8.62)$ & $5.75(2.4,13.69)^{* * *}$ \\
\hline No & $38(14)$ & $233(86)$ & 271 & 1 & 1 \\
\hline
\end{tabular}

Bold numerical values indicate significant in bivariate but not in multivariate analysis. ${ }^{*}$ Significant $(P<0.05),{ }^{* *}$ significant $(P<0.01)$, and ${ }^{* * *}$ highly significant $(P<0.001)$ in multivariate analysis.

Despite this, a study from Trinidad and Tiago, multigravida had significantly increased likelihood of being anemic than primigravidae [16]. The disparity may be as a result of sociodemographic characteristic difference between study participants. In this study, participants who were multigravida had the following characteristics. $90 \%$ had normal and above BMI, 78\% were urban residents, and $50 \%$ of them had middle and high monthly family income. These situations may reduce the risk of anemia in multigravida pregnant mothers participated in this study.

In this study, supplementation of iron sulphate, folic acid, and multivitamin during the current pregnancy period did not significantly reduce the prevalence of anemia as compared to those who did not take these supplementations. The finding was in contradiction with other studies [19$21,25,26,28]$. The possible reason may be that, in anemic pregnant women, these nutritional supplements were more likely to be prescribed as an intervention for management of anemia in their previous ANC visit. This needs a further study to explicitly explain how much effective the current $\mathrm{WHO}$ nutritional supplementation recommendation program is being implemented for prevention and control of anaemia in pregnant women [51].
4.1. Limitations of the Study. One of the limitation of this study is the nature of the study design its self, being as a cross-sectional study design, it does not show which preceded anemia or risk factors. Due to constraint of time and resource, stool concentration technique and parasite density were not done so we could not assess the impact of parasite load on the severity of anemia. In addition to this, the low sensitivity of wet mount to detect parasite in patient with low parasite load may underestimate the prevalence of intestinal parasite and alter odds ratio. The other limitation is that this study was conducted at tertiary care hospital located at Gondar town and majority of the study participants were urban residents. But many of the pregnant women in that district were living in rural areas where access to antenatal facilities is limited, so the prevalence of anemia would have been even more if the study was done in the general population.

\section{Conclusion}

In conclusion, the prevalence of anemia among pregnant women was high especially at third trimester. Mild type of anemia was the commonest one. Morphologically, 
the predominant type of anemia was normocytic normochromic, followed by microcytic hypochromic anemia. Low family income, high family size, hookworm infection, and living with HIV/AIDS were the main predictors of maternal anemia. To reduce the prevalence, there is a need to strengthen health care seeking behavior of women to ensure early diagnosis and management of HIV, hookworm, anemia, and other medical conditions. There is also a need to encourage family planning, and design policies and strategies pertinent to reduction of anemia in low income groups. A large community based study needs to be done to determine the prevalence and predictors of anemia in the general population of pregnant women. Besides, further studies using micronutrient assay techniques which are sensitive for the detection of latent anemia before the change of RBC morphology and indices takes place have to be conducted.

\section{Conflict of Interests}

The authors declare that there is no conflict of interests regarding the publication of this paper.

\section{Authors' Contribution}

Mulugeta Melku participated in designing the study, performed the data collection and statistical analysis, and was a lead author of the paper. Zelalem Addis, Meseret Alem, and Bamlaku Enawgaw participated in designing the study and helped in drafting the paper. All authors read and approved the final paper.

\section{Acknowledgments}

The authors thank all midwives and laboratory staffs who heartfully participated during data collection and laboratory analysis activities. The authors are also grateful to thank pregnant women for their voluntary participation in our study. Lastly, they would like to thank the University of Gondar and Gondar University Hospital for financial and logistics supports.

\section{References}

[1] E. McLean, M. Cogswell, I. Egli, D. Wojdyla, and B. De Benoist, "Worldwide prevalence of anaemia, WHO Vitamin and Mineral Nutrition Information System, 1993-2005," Public Health Nutrition, vol. 12, no. 4, pp. 444-454, 2009.

[2] WHO, Worldwide Prevalence of Anaemia 1993-2005: WHO Global Database on Anaemia, WHO, Geneva, Switzerland, 2008.

[3] WHO and UNICEF, Focusing on Anaemia: Towards an Integrated Approach for Effective Anaemia Control, WHO, Geneva, Switzerland, 2004.

[4] Y. Balarajan, U. Ramakrishnan, E. Özaltin, A. H. Shankar, and S. V. Subramanian, "Anaemia in low-income and middle-income countries," The Lancet, vol. 378, no. 9809, pp. 2123-2135, 2011.

[5] WHO, UNICEF, UNFPA, and World Bank, Maternal Mortality in 2005: Estimates Developed by WHO, UNICEF, UNFPA and World Bank, WHO, Geneva, Switzerland, 2007.
[6] F. W. Lone, R. N. Qureshi, and F. Emanuel, "Maternal anaemia and its impact on perinatal outcome," Tropical Medicine and International Health, vol. 9, no. 4, pp. 486-490, 2004.

[7] F. W. Lone, R. N. Qureshi, and F. Emmanuel, "Maternal anaemia and its impact on perinatal outcome in a tertiary care hospital in Pakistan," Eastern Mediterranean Health Journal, vol. 10, no. 6, pp. 801-807, 2004.

[8] H. S. Lee, M. S. Kim, M. H. Kim, Y. J. Kim, and W. Y. Kim, "Iron status and its association with pregnancy outcome in Korean pregnant women," European Journal of Clinical Nutrition, vol. 60, no. 9, pp. 1130-1135, 2006.

[9] F. Bodeau-Livinec, V. Briand, J. Berger et al., "Maternal anemia in Benin: prevalence, risk factors, and association with low birth weight," The American Journal of Tropical Medicine and Hygiene, vol. 85, no. 3, pp. 414-420, 2011.

[10] T. Kousar, Y. Memon, S. Sheikh, S. Memon, and R. Sehto, "Risk factors and causes of death in Neonates," Rawal Medical Journal, vol. 35, no. 2, pp. 205-208, 2010.

[11] B. J. Brabin, M. Hakimi, and D. Pelletier, "An analysis of anemia and pregnancy-related maternal mortality," Journal of Nutrition, vol. 131, no. 2, pp. 604S-615S, 2001.

[12] T. Marchant, J. A. Schellenberg, R. Nathan et al., "Anaemia in pregnancy and infant mortality in Tanzania," Tropical Medicine and International Health, vol. 9, no. 2, pp. 262-266, 2004.

[13] Sight and Life, "Nutritional Anemia," SIGHT AND LIFE Press, 2007, http://www.sightandlife.org/fileadmin/data/Books/ Nutritional_anemia_book.pdf.

[14] S. Ouédraogo, G. K. Koura, K. Accrombessi, F. Bodeau-Livinec, A. Massougbodji, and M. Cot, "Maternal anemia at first antenatal visit: prevalence and risk factors in a malaria-endemic area in Benin," The American Journal of Tropical Medicine and Hygiene, vol. 87, no. 3, pp. 418-424, 2012.

[15] K. Tolentino and J. F. Friedman, "An update on anemia in less developed countries," The American Journal of Tropical Medicine and Hygiene, vol. 77, no. 1, pp. 44-51, 2007.

[16] E. O. Uche-Nwachi, A. Odekunle, S. Jacinto et al., "Anaemia in pregnancy: associations with parity, abortions and child spacing in primary healthcare clinic attendees in Trinidad and Tobago," African Health Sciences, vol. 10, no. 1, pp. 66-70, 2010.

[17] B. Sukrat and S. Sirichotiyakul, "The prevalence and causes of anemia during pregnancy in Maharaj Nakorn Chiang Mai Hospital," Journal of the Medical Association of Thailand, vol. 89, supplement 4, pp. S142-S146, 2006.

[18] L. Karaoglu, E. Pehlivan, M. Egri et al., "The prevalence of nutritional anemia in pregnancy in an east Anatolian province, Turkey," BMC Public Health, vol. 10, article 329, 2010.

[19] M.-J. A. Brian, S. D. Leary, G. D. Smith, H. J. McArdle, and A. R. Ness, "Maternal anemia, iron intake in pregnancy, and offspring blood pressure in the avon longitudinal study of parents and children," The American Journal of Clinical Nutrition, vol. 88, no. 4, pp. 1126-1133, 2008.

[20] E. Fujimori, A. P. S. Sato, S. C. Szarfarc et al., "Anemia in Brazilian pregnant women before and after flour fortification with iron," Revista de Saude Publica, vol. 45, no. 6, pp. 1027-1035, 2011.

[21] S. Thirukkanesh and A. M. Zahara, "Compliance to vitamin and mineral supplementation among pregnant women in urban and rural areas in Malaysia," Pakistan Journal of Nutrition, vol. 9, no. 8, pp. 744-750, 2010.

[22] J. Haniff, A. Das, L. T. Onn et al., "Anemia in pregnancy in Malaysia: a cross-sectional survey," Asia Pacific Journal of Clinical Nutrition, vol. 16, no. 3, pp. 527-536, 2007. 
[23] L. Al-Mehaisen, Y. Khader, O. Al-Kuran, F. Abu Issa, and Z. Amarin, "Maternal anemia in rural Jordan: room for improvement," Anemia, vol. 2011, Article ID 381812, 7 pages, 2011.

[24] R. Ayub, N. Tariq, M. M. Adil, M. Iqbal, T. Jaferry, and S. R. Rais, "Low haemoglobin levels, its determinants and associated features among pregnant women in Islamabad and surrounding region," Journal of the Pakistan Medical Association, vol. 59, no. 2, pp. 86-89, 2009.

[25] Q. Zhang, Z. Li, and C. V. Ananth, "Prevalence and risk factors for anaemia in pregnant women: a population-based prospective cohort study in China," Paediatric and Perinatal Epidemiology, vol. 23, no. 4, pp. 282-291, 2009.

[26] R. Aikawa, N. C. Khan, S. Sasaki, and C. W. Binns, "Risk factors for iron-deficiency anaemia among pregnant women living in rural Vietnam," Public Health Nutrition, vol. 9, no. 4, pp. 443448, 2006.

[27] A. J. Rodríguez-Morales, R. A. Barbella, C. Case et al., "Intestinal parasitic infections among pregnant women in Venezuela," Infectious Diseases in Obstetrics and Gynecology, vol. 2006, Article ID 23125, 2006.

[28] D. A. Khan, S. Fatima, R. Imran, and F. A. Khan, "Iron, folate and cobalamin deficiency in anaemic pregnant females in tertiary care centre at Rawalpindi," Journal of Ayub Medical College, Abbottabad, vol. 22, no. 1, pp. 17-21, 2010.

[29] N. Meda, L. Mandelbrot, M. Cartoux, B. Dao, A. Ouangré, and F. Dabis, "Anaemia during pregnancy in Burkina Faso, West Africa, 1995-96: prevalence and associated factors," Bulletin of the World Health Organization, vol. 77, no. 11, pp. 916-922, 1999.

[30] D. Geelhoed, F. Agadzi, L. Visser et al., "Severe anemia in pregnancy in rural Ghana: a case-control study of causes and management," Acta Obstetricia et Gynecologica Scandinavica, vol. 85 , no. 10, pp. 1165-1171, 2006.

[31] C. C. Dim and H. E. Onah, "The prevalence of anemia among pregnant women at booking in Enugu, South Eastern Nigeria," Journal of Obstetrics and Gynaecology, vol. 26, no. 8, pp. 773776, 2006.

[32] O. Adesina, A. Oladokun, O. Akinyemi, T. Akingbola, O. Awolude, and I. Adewole, "Risk of anaemia in HIV positive pregnant women in Ibadan, South West Nigeria," African Journal of Medicine and Medical Sciences, vol. 40, no. 1, pp. 6773, 2011.

[33] M. D. Dairo and T. O. Lawoyin, "Socio-demographic determinants of anaemia in pregnancy at primary care level: a study in urban and rural Oyo State, Nigeria," African Journal of Medicine and Medical Sciences, vol. 33, no. 3, pp. 213-217, 2004.

[34] D. J. VanderJagt, H. S. Brock, G. S. Melah, A. U. El-Nafaty, M. J. Crossey, and R. H. Glew, "Nutritional factors associated with anaemia in pregnant women in northern Nigeria," Journal of Health, Population and Nutrition, vol. 25, no. 1, pp. 75-81, 2007.

[35] C. J. Uneke, D. D. Duhlinska, and E. B. Igbinedion, "Prevalence and public-health significance of HIV infection and anaemia among pregnant women attending antenatal clinics in southeastern Nigeria," Journal of Health, Population and Nutrition, vol. 25, no. 3, pp. 328-335, 2007.

[36] E. A. Achidi, A. J. Kuoh, J. T. Minang et al., "Malaria infection in pregnancy and its effects on haemoglobin levels in women from a malaria endemic area of Fako Division, South West Province, Cameroon," Journal of Obstetrics and Gynaecology, vol. 25, no. 3, pp. 235-240, 2005.

[37] T. Marchant, J. R. M. Armstrong Schellenberg, T. Edgar et al., "Anaemia during pregnancy in southern Tanzania," Annals of
Tropical Medicine and Parasitology, vol. 96, no. 5, pp. 477-487, 2002.

[38] I. Adam, A. H. Khamis, and M. I. Elbashir, "Prevalence and risk factors for anaemia in pregnant women of eastern Sudan," Transactions of the Royal Society of Tropical Medicine and Hygiene, vol. 99, no. 10, pp. 739-743, 2005.

[39] S. Gies, B. J. Brabin, M. A. Yassin, and L. E. Cuevas, "Comparison of screening methods for anaemia in pregnant women in Awassa, Ethiopia," Tropical Medicine and International Health, vol. 8, no. 4, pp. 301-309, 2003.

[40] S. Desalegn, "Prevalence of anaemia in pregnancy in Jima town, Southwestern Ethiopia," Ethiopian Medical Journal, vol. 31, no. 4, pp. 251-258, 1993.

[41] T. Belachew and Y. Legesse, "Risk factors for anemia among pregnant women attending antenatal clinic at Jimma University Hospital, southwest Ethiopia," Ethiopian Medical Journal, vol. 44, no. 3, pp. 211-220, 2006.

[42] United Nation, United Nations Millennium Declaration: Resolution Adopted By the Geneal Assembly, United Nation, Newyork, NY, USA, 2000.

[43] World Health Organization, “The World Health Report 2002: Reducing risks, promoting healthy life," 2002, http://www.who .int/whr/2002/en/whr02_en.pdf.

[44] CSA, Summary and Statistical Report of the 2007 Population and Housing Census: Population Size By Age and Sex, CSA, Addis Ababa, Ethiopia, 2008.

[45] WHO, Haemoglobin Concentrations For the Diagnosis of Anaemia and Assessment of Severity, Vitamin and Mineral Nutrition Information System, WHO, Geneva, Switzerland, 2011.

[46] M. Alem, B. Enawgaw, A. Gelaw, T. Kena, M. Seid, and Y. Olkeba, "Prevalence of anemia and associated risk factors among pregnant women attending antenatal care in Azezo Health Center Gondar town, Northwest Ethiopia," Journal of Interdisciplinary Histopathology, vol. 1, no. 3, pp. 137-144, 2013.

[47] CSA, Ethiopia Demographic and Health Survey: Preliminary Report, CSA, Addis Ababa, Ethiopia, 2011.

[48] CSA, Household Income, Consumption and Expenditure (HICE) Survey 2004/5. Volume I: Analytical Report, CSA, Addis Ababa, Ethiopia, 2007.

[49] D. H. Henry and J. A. Hoxie, "Hematologic manifestation of AIDS," in Hematology: Basic Principles and Practices, R. Hofman, E. Benz, S. Shattil et al., Eds., pp. 2585-2628, Churchill Livingstone, New York, NY, USA, 5th edition, 2008.

[50] S. Brooker, P. J. Hotez, and D. A. P. Bundy, "Hookworm-related anaemia among pregnant women: a systematic review," PLoS Neglected Tropical Diseases, vol. 2, no. 9, article e291, 2008.

[51] UNICEF, UNU, and WHO, Iron Deficiency Anemia: Assessment, Prevention, and Control, WHO, Geneva, Switzerland, 2001. 


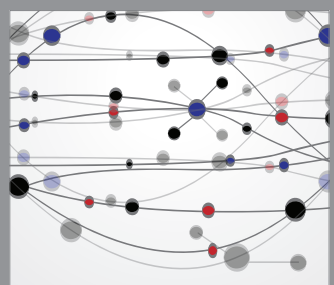

The Scientific World Journal
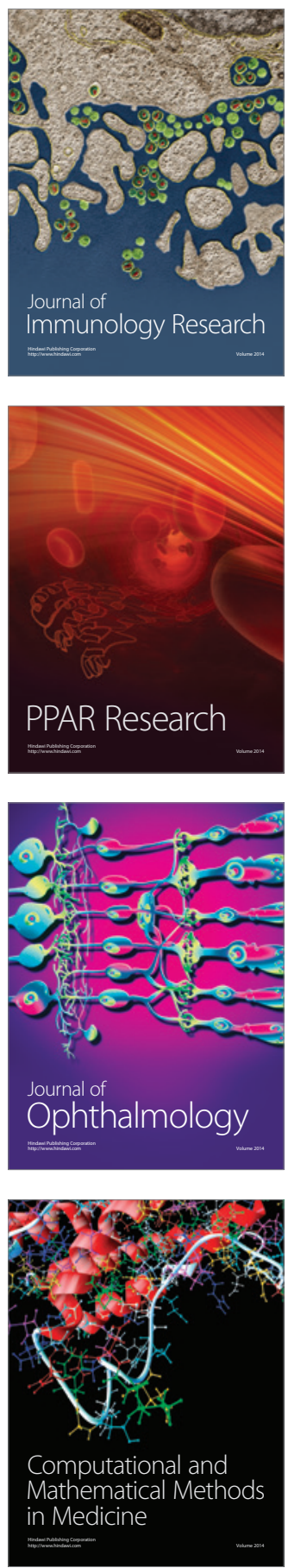

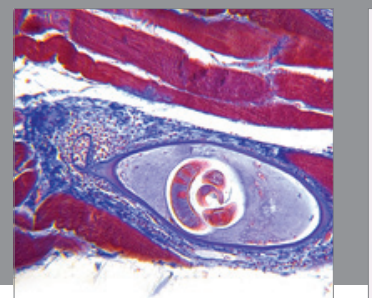

Gastroenterology

Research and Practice
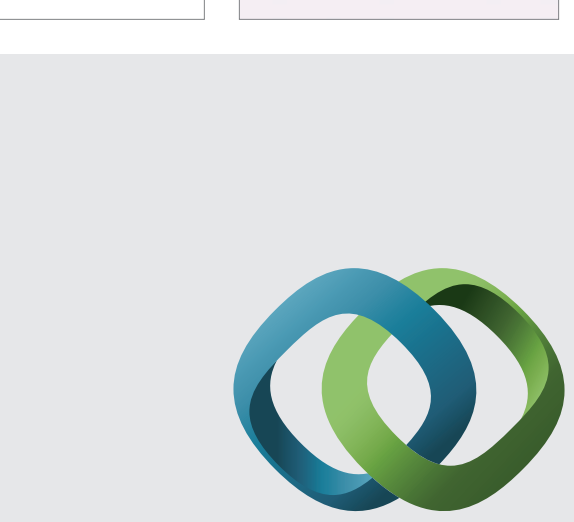

\section{Hindawi}

Submit your manuscripts at

http://www.hindawi.com
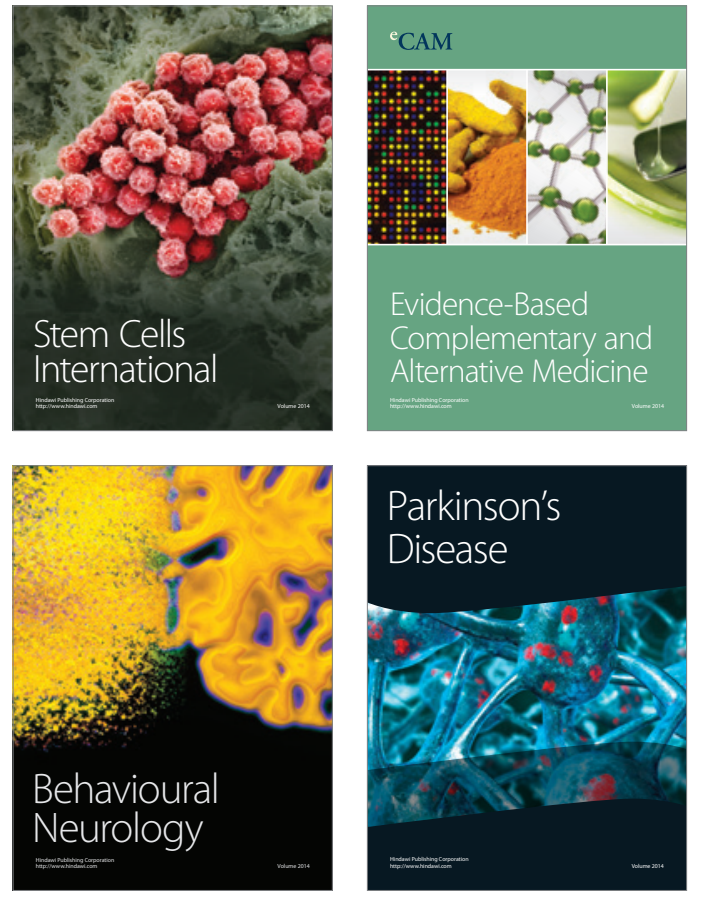
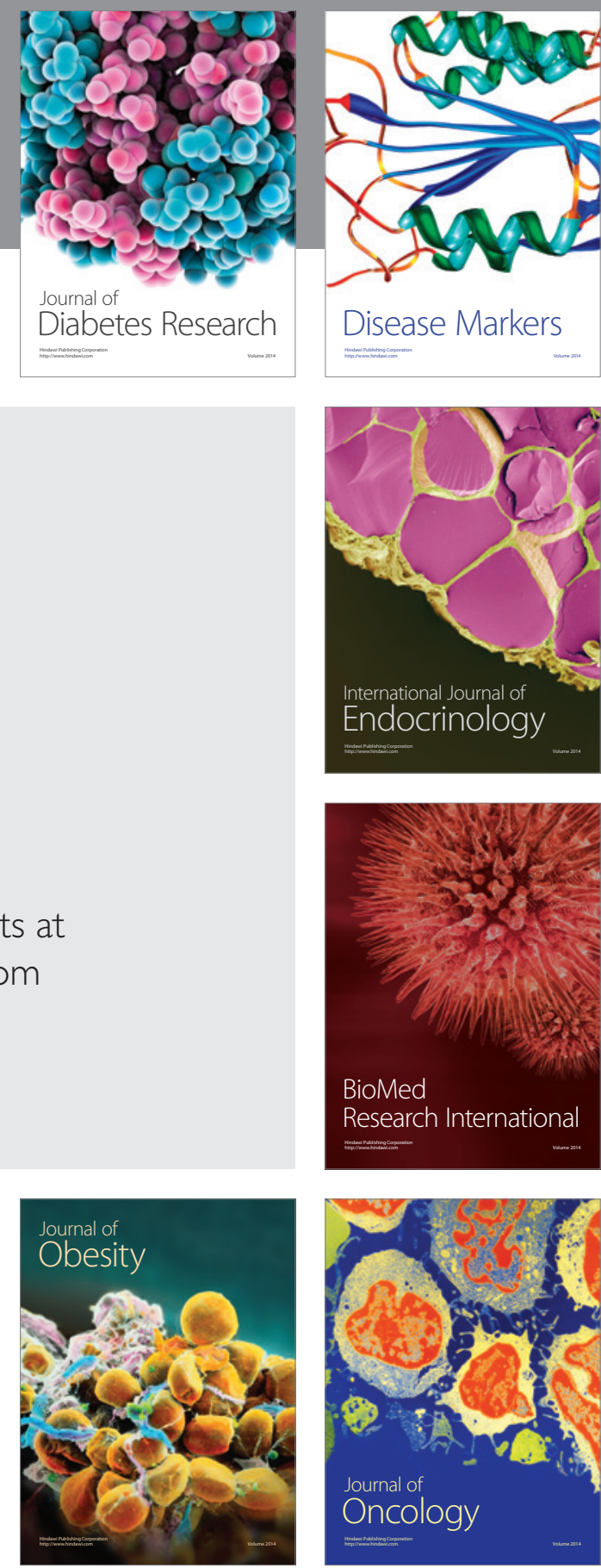

Disease Markers
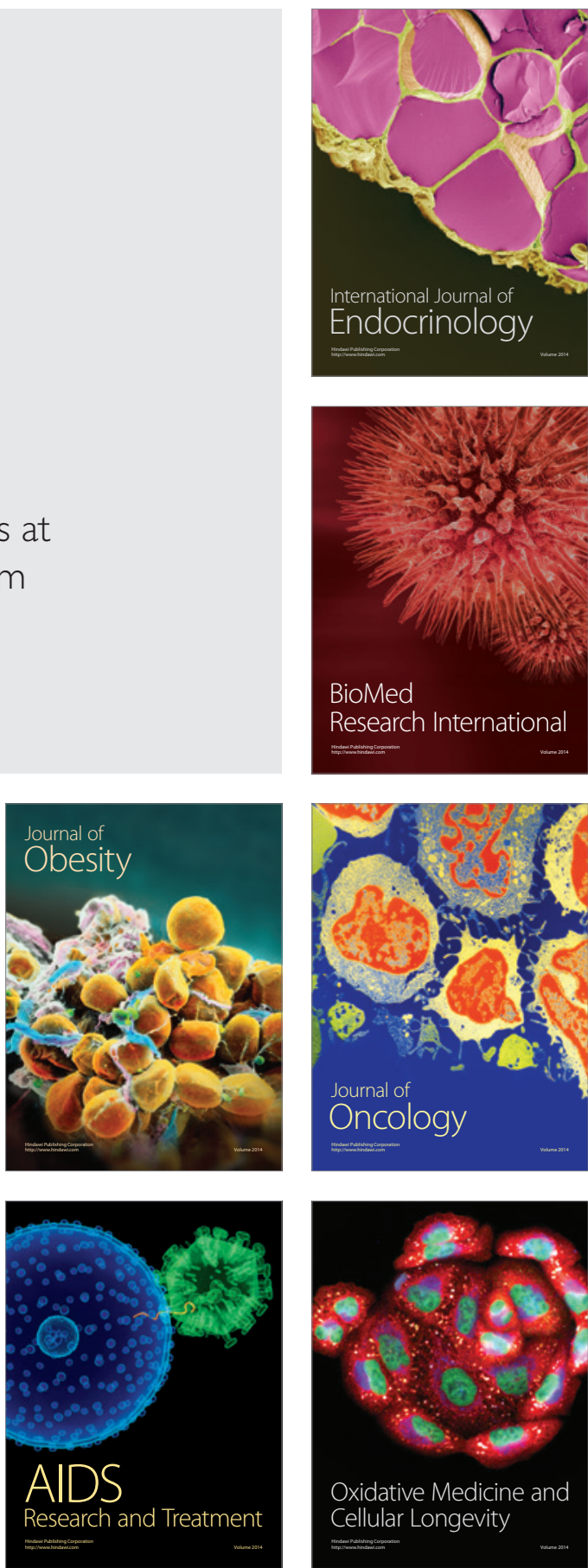